\title{
A AUTOCOMPOSIÇÃO NOS CONFLITOS JUDICIAIS
}

SELF-COMPOSITION IN JUDICIAL CONFLICTS

Nívea Maria Santos SOUTO MAIOR ${ }^{1}$

ISSUE DOI: $10.21207 / 1983.4225 .510$

\section{RESUMO}

O presente artigo visa ao estudo da autocomposição como resolução apropriada para conflitos judiciais. Primeiramente, cumpre a missão de traçar um arcabouço histórico e legislativo descrevendo a virada cultural do litígio para pacificação. Em seguida, são analisadas algumas espécies autocompositivas aplicadas nos conflitos levados ao Poder Judiciário, a exemplo da mediação e conciliação. Ao final, concluem-se as vantagens da autocomposição como obtenção de uma Justiça mais célere visando o empoderamento das partes e a satisfação de seus reais interesses.

Palavras-chaves: Teoria moderna do conflito. Poder Judiciário. Autocomposição.

\section{ABSTRACT}

This paper aims to study self-composition as an appropriate resolution for judicial conflicts. First, it fulfills the mission of drawing up a historical and legislative framework describing the cultural turn of the dispute for pacification. Then, some self-compositional species applied in conflicts brought to the Judiciary are analyzed, such as mediation and conciliation. In the end, the advantages of selfcomposition are concluded, such as obtaining a faster Justice aiming at the empowerment of the parties and the satisfaction of their real interests.

Keywords: Modern conflict theory. Judicial power. Self-composition.

\footnotetext{
${ }^{1}$ Mestrado em Serviço Social pelo PPGSS da Universidade Estadual da Paraíba (UEPB), João Pessoa/PB. Mestrado em Direito pela Universidade Estácio de Sá (UNESA). Pós-graduada em Direito do Trabalho e Direito Processual do Trabalho pela Universidade Cândido Mendes (UCM) Rio de Janeiro/RJ. Graduada em Direito pela Universidade Estadual da Paraíba (2005). Atualmente é proprietária - Vieira Souto Advogados Associados. Membro da Comissão da Advocacia Trabalhista OAB Subseção Campina Grande/PB (triênio 2016/2018). Tem experiência na área de Direito, com ênfase em Direito do Trabalho e Direito Previdenciário. Currículo Lattes: http://lattes.cnpq.br/8837507427556940. Contato: legaliteadv@ yahoo.com.br.
} 
1

\section{INTRODUÇÃO}

Em março de 2016, disse o Ministro do Supremo Tribunal Federal Teori Zavaski: "o papel do juiz é resolver conflitos e não criá-los". Dito isto, cabe a cada um questionar: para que serve o Direito? Se a resposta for a pacificação social, surge em sequência outra interrogação: o Direito resolve de fato os conflitos?

O jurista argentino Remo Entelman estudou o conflito como uma espécie do gênero das relações sociais, articulando, em linhas gerais, que tais relações contêm uma incompatibilidade aparente, percepções de atitudes hostis entre duas ou mais pessoas.

O conflito é um fenômeno natural entre seres vivos, é inerente à vida, faz parte do amadurecimento das relações. E para solucionar um conflito nem sempre será necessário a judicialização do mesmo, como também não precisa ter uma única parte vencedora.

A teoria moderna do conflito propõe um olhar positivo sobre o tema, cuja abordagem ultrapassa o ramo da ciência jurídica, e seu estudo deve ser multidisciplinar, exige o conhecimento de outros ramos do saber, a exemplo da psicologia e da neolinguística.

À vista disso, a solução apropriada de um conflito levado ao Judiciário deve ir além do campo normativo, haja vista a complexidade do conflito em si, que pode ser ilustrada como a figura de um iceberg, sendo as relações sociais e processuais apenas a ponta do iceberg (a parte visível), havendo ainda uma grande parte submersa representando a dimensão subjacente do conflito.

Nos tempos hodiernos, existe uma crise institucional no Poder Judiciário, a sociedade está descrente em ter uma resposta judicial para seus anseios. Muitas vezes, após anos de tramitação, existe a entrega da prestação jurisdicional por meio de uma sentença, mas ainda sim remanesce a litigiosidade, principalmente a lide sociológica (os interesses subjacentes das partes). Em resumo: os processos são julgados, porém as partes não resolvem suas pendências emocionais, fruto dos seus reais interesses.

É necessário mudar o rosto do Poder Judiciário, reverter o paradigma de "juiz de gabinete" como aquela pessoa tirana, 
aparentemente despreocupado com a resolução do conflito, impositivo em aplicar a lei. O ideal seria tê-lo como um "facilitador da justiça do caso" que é uma pessoa criativa, privilegiador dos fins do processo, preocupada com a realidade resultante daquela vivência experimentada perante o Judiciário.

A autocomposição pode ser definida como uma forma de solução de conflitos alcançada através de um ajuste de vontades entre as partes, trata-se da devolução aos sujeitos de sua titularidade na solução de seu próprio problema.

O psicólogo Juan Carlos Vezzulla (2004), com bastante lucidez, descreve a autocomposição como:

De grande importância é a introdução desse método que procura substituir a imposição, o uso da força e a tentativa de tirar vantagens dentro do conceito ganha-perde de exclusão, substituindo-o pelo respeito, a responsabilidade e a cooperação, baseado no ganhaganha.

Esse meio de solução de conflito precisa ser visto como principal política pública do Judiciário, em virtude de a conciliação ser uma forma de mostrar que o serviço público funciona bem, que os impostos estão sendo bem empregados na função de harmonização dos conflitos.

Anualmente, o CNJ (Conselho Nacional de Justiça) publica um relatório chamado "justiça em números", que divulga a realidade dos tribunais brasileiros. Uma das estatísticas utilizadas chama-se taxa de congestionamento, que é o percentual de processos baixados em detrimento aos novos processos, e por anos consecutivos esta taxa teve seu saldo sempre negativo.

No ano de 2015, entretanto, foi a primeira vez em que se contabilizou a queda no número de casos que chegam à Justiça, quer dizer, os baixados superaram os novos, sofrendo uma espécie de retração. Os dados acima apontam para a chamada virada cultural, a mudança da era do litígio para os tempos de paz através das técnicas de composição dos conflitos não adversariais ou autocompositivos, ou seja, mais acordos e menos julgamentos.

\section{EVOLUÇÃO HISTÓRICA E LEGISLATIVA}


Os meios de solução de conflitos, antes de serem reconhecidos como institutos jurídicos, já existiam desde os primórdios, a exemplo da medição, cujo termo foi utilizado na Bíblia: "Porque há um só Deus, e um só Mediador entre Deus e os homens, Jesus Cristo homem” (I Timóteo, capítulo 2, versículo 5).

A autotutela tem sua origem em civilizações primitivas, quando cabia ao particular sobrepor o seu direito ao dos demais indivíduos, representando a prevalência do mais forte, visto que inexistia um órgão estatal, tal como narrava o cientista Charles Darwin em seu livro "A Origem das espécies".

Em 1824, a Constituição Imperial de nosso país, já previa em seu artigo 161: "Sem se fazer constar que se tem intentado o meio de reconciliação, não se começará processo algum”.

Porém ao longo do tempo, houve o estímulo do acesso ao Judiciário como única forma de solução de conflito, a exemplo do que previa a nossa primeira Constituição republicana (1891).

A atual Constituição Federal (1988) continuou a estimular a população a reivindicar seus direitos perante o Poder Judiciário, objetivando ser protagonista na solução de conflitos. Após décadas da sua promulgação, tornou-se inviável o Estado administrar a máquina judiciária, cabendo ao magistrado gerir o imenso volume de processos: um grande número de causas simples e demandas repetitivas, com um pequeno número de causas complexas.

Diante disto, importante adotar o abrandamento do princípio da inafastabilidade da jurisdição, previsto no artigo $5^{\circ}$, inciso XXXV, da Constituição Federal, como sendo o único poder capaz de dizer o direito com força de coisa julgada.

Em 2006, um dos primeiros passos para a virada da cultura da paz foi o lançamento do movimento "conciliar é legal", preconizado pela Ministra Ellen Gracie que à época era presidente do STF, o projeto tratavase de uma mobilização dos tribunais para fomentar a conciliação entre as partes, incentivando como o melhor caminho para o encerramento de um processo.

Este projeto foi aderido pelos Tribunais de Justiça, que reserva a cada ano a Semana Nacional de Conciliação com inúmeras ações para disponibilizar as partes interessadas a realização de acordos, independente de qualquer fase processual. 
Outro marco foi a criação da Resolução $\mathrm{n}^{\circ} 125$ do $\mathrm{CNJ}$, que estabeleceu uma metodologia e uniformização para a resolução de conflitos de forma não litigiosa, incumbindo aos órgãos judiciais oferecer meios alternativos para a resolução de controvérsias.

De acordo com o artigo $7^{\circ}$ da resolução 125/2010, os Tribunais devem criar os Núcleos Permanentes de Métodos Consensuais de Solução de Conflitos (NUPEMEC), os quais serão um "centro de inteligência" que deverão desenvolver uma política judiciária de tratamento adequada ao conflito, assim como capacitar conciliadores e mediadores sobre os métodos consensuais de solução de conflitos.

Em sintonia com a política pública de consensualização do Poder Judiciário, houve a publicação do novo Código de Processo Civil prestigiando a conciliação e a mediação como modalidades de autocomposição, para que assim a jurisdição não seja a única forma de solução de conflitos.

O jurista italiano Mauro Capelletti cuidou do interesse em torno do problema do acesso à justiça, resumindo em três ondas os principais movimentos renovatórios: primeira, a assistência judiciária para os pobres; segunda, a representação judicial dos interesses difusos/coletivos; e, terceira, a construção de um novo modelo, com respostas diversificadas diante da complexidade do tema. No último aspecto, ganha importância a adoção de meios alternativos de composição do conflito.

Esta terceira onda de acesso à justiça, além de apresentar vertente constitucional (artigo $5^{\circ}, \mathrm{XXXV}$, da Constituição Federal), tem como alvo o "obstáculo processual", ante a ineficácia do processo contencioso para dar uma solução eficaz ao problema. Por mais que todos os juízes e desembargadores façam um esforço extraordinário, eles não conseguiram julgar os processos com a velocidade que a prestação jurisdicional é esperada.

A expressão "sistema multiportas" é uma inovação que direciona os processos que chegam a um tribunal para o mais apropriado método de resolução de conflitos, economizando tempo e dinheiro, tanto para os tribunais quanto para as partes.

A dificuldade ao acesso à justiça está na maneira pela qual buscamos justiça, ou seja, em qual porta batemos para achá-la. Destarte, a ideia do sistema multiportas é examinar as diferentes formas de resolução de conflitos (mediação, arbitragem, conciliação) e verificar qual seria a "porta" mais adequada para solucionar o caso concreto. 
É justamente por isso que alguns estudiosos não gostam de usar o nome "alternativo" e sim "adequado" (Resolução Apropriada de Disputas - RAD), porque dá a entender que só faria uso se o principal não desse certo, e na verdade tudo é apropriado o que se precisa analisar é qual a melhor técnica para cada caso.

Logo, o sistema multiportas surge com grande eficiência na resolução dos conflitos interpessoais, pois são as próprias partes que encontram as soluções, somado ao fato da celeridade e eficácia dos resultados, além da redução do desgaste emocional das partes.

\section{DAS FORMAS DE SOLUÇÃO DE CONFLITOS}

Conforme a clássica lição de Francesco Carnelutti, a lide é "um conflito de interesses qualificado por uma pretensão resistida", significa um choque de forças contrárias de feição intersubjetiva (entre sujeitos), e uma vez diante da lide há de existir uma solução para ela. O nosso ordenamento jurídico contempla alguns modos de solução de conflitos, a saber: a heterocomposição, a autodefesa e autocomposição.

$\mathrm{Na}$ heterocomposição soluciona-se um conflito por uma fonte supra partes, ou seja, ocorre a intervenção de um terceiro que vem a decidir a controvérsia, impondo a solução aos litigantes. E a autodefesa refere-se à imposição de uma das partes perante a outra, a solução se dá através da supressão da vontade de uma das partes.

Já na autocomposição, o conflito é solucionado pelas próprias partes, mediante um ajuste de vontades. Os métodos autocompositivos de solução de conflitos - como são a mediação e a conciliação, conhecidos também pela sigla MASC ou, no idioma inglês, de ADR (Alternative Dispute Resolution) estão em notória expansão no mundo inteiro.

\subsection{ARBITRAGEM}

A arbitragem trata-se de método heterocompositivo, de forma extrajudicial e voluntária, em que as pessoas envolvidas num conflito delegam poderes a um árbitro, geralmente especialista na matéria, para decidir por elas o litígio. 
O Brasil tem norma específica sobre a arbitragem ${ }^{2}$, sendo recentemente reformada pela lei $\mathrm{n}^{\circ} 13.129 / 2015$; e o STF já reconheceu a sua constitucionalidade ${ }^{3}$, ou seja, uma decisão arbitral tem o mesmo valor que uma decisão judicial.

Outrossim, o Poder Judiciário somente será acionado se uma das partes não cumprir a sentença arbitral, neste caso ocorrerá a execução forçada por meio de um processo judicial.

Inclusive o Código de Processo Civil, em seu artigo 235, inciso IV, criou a figura da carta arbitral, que consiste no instrumento pelo qual o árbitro solicita a cooperação do Poder Judiciário para praticar ou determinar o cumprimento de decisão, na área de sua competência territorial.

Além disso, o estímulo à adoção da arbitragem pode ser observada nos contratos em geral, em que é fixada uma cláusula ao final do pacto, com os seguintes dizeres: "Todas as questões oriundas deste contrato serão dirimidas por meio de mediação ou arbitragem, ficando desde logo escolhida a Câmara de Mediação ou Arbitral X ou Y”.

Destaca-se ainda que o Superior Tribunal de Justiça (STJ), através de seu informativo $\mathrm{n}^{\mathbf{0}}$ 591, já pronunciou que esta cláusula compromissória terá eficácia desde que escrita em anexo ao contrato de adesão ou grifada em negrito.

\subsection{MEDIAÇÃO}

A mediação é uma técnica de solução de conflitos no qual um terceiro ajuda as partes a conversar, entender o conflito e buscar, por elas próprias, a solução. Em outras palavras, as partes por si só tomam a decisão, agindo o mediador como um facilitador na busca de um denominador comum entre as pretensões das partes.

O mediador deve tentar ser neutro, não pode polarizar com as partes, tem que se policiar em relação às suas expressões para não demonstrar tendência a uma das partes.

\footnotetext{
2 BRASIL. Lei $\mathrm{n}^{\text {o }}$ 9307, de 23/09/1996. Disponível em: <http://www.planalto.gov.br/ccivil_03/leis/L9307.htm>. Acesso em: 13 fev. 2017.

${ }^{3}$ SUPREMO TRIBUNAL FEDERAL. SE 5206 AgR, Relator(a): Min. SEPÚlVEDA PERTENCE, Tribunal Pleno, julgado em 12/12/2001, DJ 30-04-2004.
} 
$\mathrm{Na}$ seara legislativa, a mediação é disciplinada pela Lei $\mathrm{n}^{\circ}$ 13.140/2015. Na mediação extrajudicial, as partes escolhem livremente o mediador, pode ser qualquer pessoa capaz que tenha a confiança das partes e seja capacitada (artigo $9^{\circ}$ da lei).

Diferente é a mediação judicial, no qual os Tribunais manterão registro de conciliadores e mediadores, com indicação de sua área profissional, estes profissionais precisam possuir graduação há pelo menos dois anos em curso de ensino superior, como também ter participado de curso de capacitação em escola ou instituição de formação, observado outros requisitos estipulados pelo CNJ.

Outro aspecto é que os mediadores e conciliadores que atuam no âmbito judicial são considerados auxiliares da justiça, e por isso são submetidos aos mesmos impedimentos e suspeições aplicáveis ao magistrado, bem como é equiparado a servidor público para fins penais.

A mediação possui algumas características e princípios peculiares, dentre eles, cabe destacar a confidencialidade (artigo 166, $\S 1^{\circ}$, $\mathrm{CPC})$ que é a promessa do sigilo dos fatos revelados pelas partes, salvo poucas exceções, como, por exemplo, se a informação tratar da ocorrência de um crime de ação pública.

Em agosto de 2016 ocorreu a I Jornada "Prevenção e Solução Extrajudicial de Litígios", cujo evento foi de responsabilidade do Conselho da Justiça Federal (CJF), sendo aprovados 87 enunciados sobre o tema, cabendo destacar ao final o seguinte enunciado:

MEDIAÇÃO

$\mathrm{N}^{\mathrm{o}} 14$ - A mediação é método de tratamento adequado de controvérsias que deve ser incentivado pelo Estado, com ativa participação da sociedade, como forma de acesso à Justiça e à ordem jurídica justa.

\subsection{CONCILIAÇÃO}

É uma forma de solução de conflitos em que as partes, por meio da ação de um terceiro, chegam a um acordo, solucionando a controvérsia. Nesse caso, o conciliador terá a função de orientá-las e ajudá-las, fazendo sugestões de forma que melhor atendam aos interesses dos dois lados em conflito. 
A diferença crucial entre a mediação e a conciliação é o nível de intervenção do terceiro, o conciliador propõe saídas para a solução da lide, o que não temos na mediação. Porém, em ambas as técnicas as partes continuam com sua autonomia no que diz respeito à solução proposta, tendo a liberdade de aceitar ou não o acordo.

A conciliação pode ocorrer em diversos momentos, quando o processo já estiver instaurado a qualquer tempo poderá haver acordo entre as partes (artigo 139, V, CPC). Na fase pré-processual, o objetivo é preventivo, evita-se uma ação judicial quando não é necessária, nesta hipótese é realizada uma sessão entre as partes que são convocadas através de carta convite.

Veja que o artigo 319, inciso VII, do CPC inova como requisito da petição inicial a manifestação expressa quanto ao interesse na composição consensual, em virtude de que a audiência de conciliação ou mediação não será realizada tão-somente se ambas as partes recursarem ou quando o litígio não se admitir a autocomposição.

Por fim, em relação aos advogados, a autocomposição também tem sido festejada pela $\mathrm{OAB}$ e em evidência está no novo Código de Ética e Disciplina da $\mathrm{OAB}^{4}$, que prevê a proibição de diminuição dos honorários advocatícios se for adotado solução extrajudicial ao litígio (artigo 48, $\S 5^{\circ}$ ), introduz a figura dos "honorários conciliatórios" como substituto dos "honorários sucumbenciais".

\section{CONSIDERAÇÕES FINAIS}

Mahatma Gandhi dizia "olho por olho e o mundo acabará cego". O fato é que não se deve ter a preocupação de quem está certo ou errado, mas sim achar a solução adequada do caso. Um conflito administrado de forma positiva deve ter dois vencedores (negociação ganha-ganha), buscar a satisfação real de ambas as partes e resolver quando possível a lide sociológica.

Os operadores do Direito precisam abandonar velhos hábitos profissionais com menos domínio erudito e mais diálogo, quiçá aprende-se Direito entendendo de gente e não de normas.

\footnotetext{
4 BRASIL. Resolução $\mathrm{n}^{\mathrm{o}}$ 02/2015, DOU 04/11/2015, p. 77. Disponível em: <http://www.oab.org.br/Content/pdf/novo-ced.pdf>. Acesso em: 13 fev. 2017.
} 
Portanto, a autocomposição implantou uma nova era no Poder Judiciário Brasileiro, solucionando o seu anquilosamento, bem como restaurando os relacionamentos interpessoais e reduzindo a conflituosidade no seio social, os sujeitos estão aptos a definir pela livre disposição da vontade, a melhor "sentença" que lhes sirva a seus interesses.

\section{REFERÊNCIAS BIBLIOGRÁFICAS}

AZEVEDO, André Gomma de. Perspectivas metodológicas do processo de mediação: apontamentos sobre a autocomposição no direito processual. In: AZEVEDO, André Gomma de (org.). Estudos em Arbitragem, Mediação e Negociação. Brasília/DF: Grupos de Pesquisa, 2003. v. 02, p. 152-153

CAPPELLETTI, Mauro; GARTH, Bryant. Acesso à Justiça. Porto Alegre: Sérgio Antonio Fabris Editor, 1998.

CONSELHO NACIONAL DE JUSTIÇA. Justiça em Números. 2016 (ano-base 2015). Disponível no site <http://www.cnj.jus.br/programas-e-acoes/pj-justica-em-numeros>. Acesso em 08/12/2016.

DIDIER, Fredie. Curso de Direito Processual Civil, Volume 1. 16.ed. Salvador: Juspodivm, 2014. 620 p.

DINIZ, Bárbara. Mediação Judicial. Portal Jurídico Investidura, Florianópolis/SC, 04 Mar. 2009. Disponível no site <www.investidura.com.br/biblioteca-juridica/artigos/empresarial/2901>. Acesso em: 05 Mar. 2017

EGGER, Ildemar. Mediação comunitária popular: uma proposta para além da conflitologia. Tese de Doutorado, CPGD/UFSC. Florianópolis/SC: abril/2008.

SILVA, Homero Batista Mateus da. Técnicas de mediação para o aprimoramento do processo do trabalho. Revista do Advogado, São Paulo, v. 34, n. 123, p. 105-114, ago/2014.

SILVA, João Alves. Teoria de conflitos e direito: em busca de novos paradigmas. Revista Pensar, Fortaleza, v. 13, n. 2, Jul./dez. 2008.

VEZZULLA, Juan Carlos. A mediação de conflitos com adolescentes autores de ato infracional. Dissertação de Mestrado, UFSC. Florianópolis/SC: 2004.

VIANNA, Marcio dos Santos. Mediação de conflitos: um novo paradigma na administração da justiça. Âmbito jurídico, Rio Grande, XII, n. 71, dez 2009.

WIKIPEPIA ENCICLOPÉDIA LIVRE. Autocomposição. Disponível no site <https://pt.wikipedia.org/wiki/Autocomposição>. Acesso em 27/01/2017. 